\title{
Childhood Adversity, Attachment Security, and Adult Relationships: A Preliminary Study
}

\author{
Elizabeth M. Hill, James P. Young, and Janet L. Nord \\ The University of Michigan Alcohol Research Center, Department of Psychiatry, \\ University of Michigan, Ann Arbor
}

\begin{abstract}
Several evolutionary theorists have linked early rearing context to later reproductive strategy, hypothesizing that strategies differentiate during development as functional responses to ecological characteristics, by individuals or through parental manipulation. Attachment security has been proposed as a mediator. In this study, 40 young adults were given a multidimensional assessment, including the Hazen and Shaver Adult Attachment Questionnaire. Twenty-four subjects were classified as having secure attachment styles, 16 as nonsecure. The magnitude and predictability of parental investment during childhood was classified as lower if there was a brief intersibling interval, parental divorce, fewer economic resources, or less nurturing parents (i.e., more childhood adversity). Several such indicators were present for 17 people, 12 of whom were nonsecure, compared to only 4 of the 23 others. The nonsecurely attached subjects were less likely to have attained enduring marriages. The $6 / 16$ nonsecure who had a marriage or cohabitation began them at a younger age and after a shorter courtship period than did the $15 / 24$ secure with such relationships. Separations or divorces had already occurred in the relationships of $4 / 6$ nonsecure versus $5 / 15$ secure. Attachment security was associated with childhood adversity and adult relationships for both men and women, when analyzed separately. A retrospective study cannot address cause and effect, because poor adult relationship outcomes might bias recall of parental behavior. However, results are consistent with theories that unpredictable early environments foster short-term rather than long-term mating strategies, possibly through affecting attachment styles.
\end{abstract}

KEY WORDS: Attachment; Reproductive strategies; Parental investment; Childhood resource adversity; Relationships

\section{INTRODUCTION}

Evolutionary theory predicts that life history strategies will be related to environmental conditions (Emlen and Oring 1977; Krebs and Davies 1984). Received June 15, 1994; revised September 17, 1994.

Address reprint requests and correspondence to: Elizabeth M. Hill, Ph.D., The University of Michigan Alcohol Research Center, Department of Psychiatry, 400 E. Eisenhower, Ann Arbor, MI 48104 U.S.A. 
The components of reproductive life histories that may vary include the amount of parental effort expended, sex differences in parental effort, and distribution of investment between own reproduction and helping one's kin. The optimal timing of mating and parental effort during the life cycle is a key variable that differentiates reproductive life-history strategies (Hirschfield and Tinkle 1975; Williams 1966). Variability in behavior, both between and within populations, may be affected by environmental conditions; the spatial and temporal distribution of resources affects which reproductive strategies are most likely to be successful (Emlen and Oring). For example, long-term cooperation of a mating pair in rearing offspring may be advantageous for both parents when environmental resources are uniformly distributed and defensible; however, resources sufficient to support a pair cannot be defended if distributed too sparsely and widely (Emlen and Oring). Using a life-history perspective, Borgerhoff Mulder (1992) has recently reviewed factors that affect costs and benefits of several parental care-allocation schemes for humans.

Several evolutionary theorists have hypothesized that several distinctive patterns of reproductive investment exist in humans (Dickemann 1986; Belsky et al. 1991; Draper and Belsky 1990; Draper and Harpending 1981; Lancaster and Lancaster 1987). These authors have proposed that early rearing context affects later reproductive strategy, such that individuals respond functionally to ecological characteristics of their developmental environment (recently articulated by Belsky et al.; Dickemann; Draper and Belsky). These authors propose that stressful, unpredictable environments set people on a course to reproduce early and to have parental or child-rearing relationships that are only transiently cooperative (Belsky et al.; Draper and Belsky). These arguments are consistent with the work of Surbey (1990), which documented early menarche by young women from homes with ahsent fathers.

Studies in the ethology and behavioral ecology of animal life histories support the notion that environmental unpredictability affects reproductive strategies. When the environment is unpredictable, one's future chances for reproducing are also unpredictable; the best strategy may be to reproduce when some resources become available (Hill and Low 1992; Rubenstein 1982). In these situations, it is not advantageous to save resources for future use or invest them in one's own further growth and development (Rubenstein). When there are high adult failure rates for various reasons (mortality, competitive failure), an alternate strategy of opportunistic breeding when young may be best (Dickemann 1986). Burton (1990) interpreted the pattern seen commonly in poor neighborhoods - of early childbearing with grandmaternal care of children-as a functional response to low survival rates in an environment where traditional patterns are not feasible. In this alternative life-course strategy, there are additional elements of separation of marriage from reproduction, and childbearing by only some siblings in a generation, with others working and contributing resources (Burton).

Draper, Belsky, and colleagues (Belsky et al. 1991; Draper and Belsky 1990) proposed a mediating role for attachment security in the relationship 
between early environment and one's own reproduction, while Dickemann (1986) described mediation through multiple gender identities. Draper and Belsky proposed that the "internal working model" of relationships that children develop from early interactions with caretakers affects their later expectations that other relationships will be rewarding and enduring, in particular, whether a marital partner can be "counted on" over the long haul (Draper and Belsky, p. 152). Empirical research has documented some of these associations. Insecure or mistrustful internal models of relationships are more probable when behavior of caretakers has been harsh or unpredictable; in turn, such parental behavior is more likely when conditions are stressful (Ainsworth et al. 1978; Bowlby 1969; Sroufe 1979).

Chisholm (1993) has presented a similar conceptual model of the relationship between local mortality rate, attachment style, and short- versus long-term mating patterns. He elaborated on the role of mortality rate, using proposals of Promislow and Harvey $(1990,1991)$ that life-history traits are affected by the intensity and age-specificity of mortality rates. In this model, high mortality produces proximate stress for parents, which results in emotional stress for children. In turn, early psychological stress affects attachment patterns, predisposing one toward a reproductive strategy of lower parental investment (psychologically, a "less involved style of parenting"; Chisholm 1993, p. 10). The concept of "early stress" allows incorporation of existing psychological literature, but it is vague. The interconnections in this model would be clearer if the amount and predictability of parental investment and other aspects of the resource environment are used instead of "early stress." Chisholm also assumes that children do not directly sense mortality rates, while they certainly do witness violence and accidents, and are aware of the deaths of significant individuals or neighbors (Bell and Jenkins 1993).

Our model of the interrelationships among early environment, attachment security, and adult relationships is shown in Figure 1. The salient dimensions of early environment are the predictability and amount of parental investment. Adult relationships are expected to vary by timing and duration. Measures are discussed in detail below. Early childhood experiences are hypothesized to correlate with attachment security, which influences adult relationships. This model has similarities to the one published by Draper and Belsky (1990), which was further refined by Belsky et al. (1991). Parent-child relationships figured in their model, which emphasized father absence. Their reproductive measures included timing of puberty, stability of adult-pair bonds, degree of parental investment in children, and $r$-selected versus $k$-selected life-history strategies. In refinements, discussion of $r$ - and $k$-strategies have been eliminated, and Belsky et al. focused instead on variation along a continuum of parental investment of "quality versus quantity." Our model, rather, focuses on the effect of early environmental unpredictability, whatever the source, on timing of first attempt to form marital reproductive relationships.

During a study comparing 20 young adults who each had an alcoholic parent to 20 young adults with social-drinking parents, subjects were given 


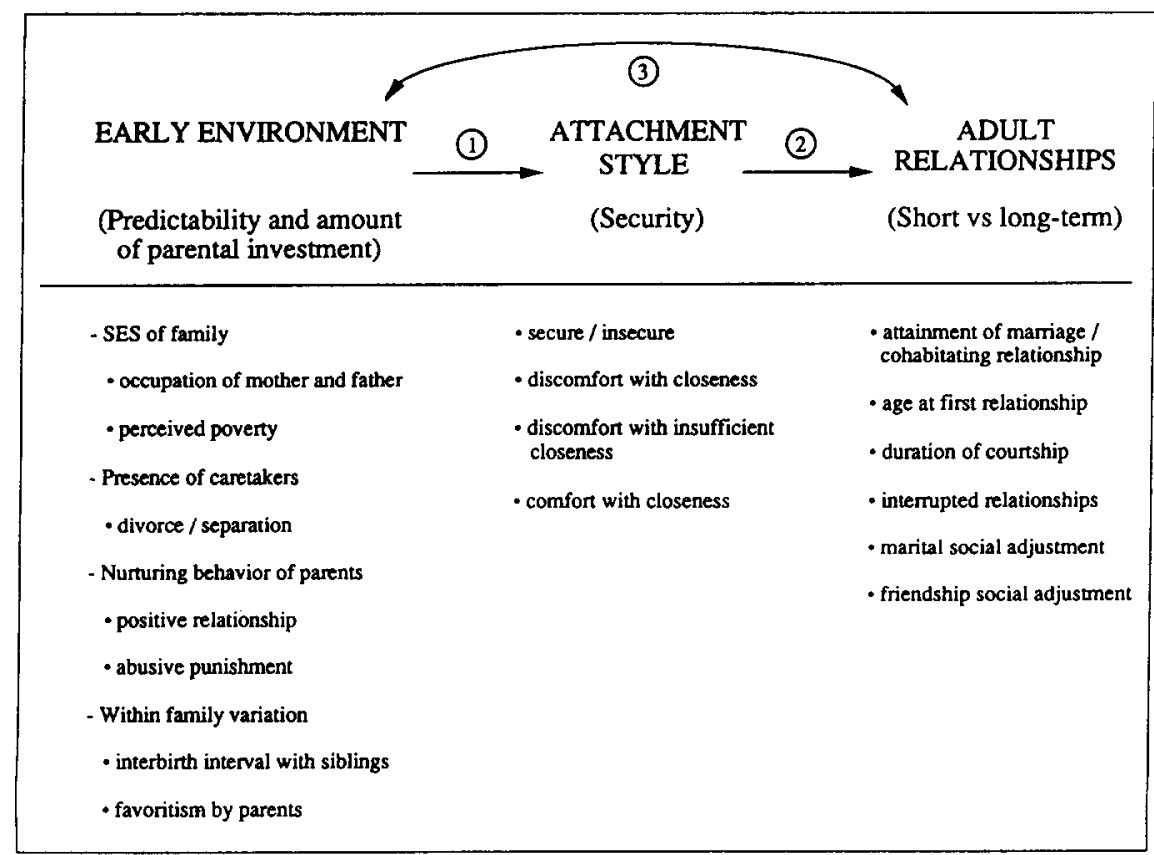

FIGURE 1. Conceptual model of the relationships among attachment security, early environment, and adult relationships.

additional assessments to address some aspects of our model of the interrelationships of early rearing environment, attachment security, and reproductive behavior as a young adult. Originally, we expected that children of an alcoholdependent parent would have less secure attachment, and that attachment security would correlate with the participants' drinking problems. Neither hypothesis was supported; so groups were collapsed for the analysis presented here. This paper contrasts those subjects with secure attachment $(n=24)$ to those nonsecurely attached $(n=16)$, showing the relationship of adult attachment security to early childhood adversity and to some adult reproductive measures.

\section{METHODS}

\section{Participants}

Young-adult subjects were 20 men and 20 women, ranging in age from 18-30 $(\bar{x}=24.8 \pm 3.8)$. Most completed high school and were currently employed with incomes in the $\$ 10,000-14,999$ or $\$ 15,000-19,999$ range. All ramilies were Caucasian, except one. The original groups of young adults and their parents have been described in detail elsewhere (Hill et al. 1992). Parents were in their mid-fifties, and most had more than one marriage. Demographic differences between alcohol-dependent and social-drinker parents were negligible, except that alcohol-dependent parents tended to be less educated. These 
two groups were pooled for the analyses reported here, since alcohol-dependence in a parent did not affect the subjects' attachment security, as noted above.

\section{Procedure}

Participants were recruited by contacting eligible parents who were already participating in research studies at the University of Michigan Alcohol Research Center (UMARC). UMARC participants are recruited by a variety of means, including placing advertisements in local newspapers, interviewing patients in treatment at several local alcoholism treatment programs, and direct mailings to various groups, such as university alumni or service organizations. Eligible subjects from this pool were asked to consent to contact children and to provide telephone numbers. The consent rate of the 45 parents contacted was $89 \%(n=40)$. We recruited 20 parents who were alcohol dependent and 20 who were social drinkers, as determined by structured diagnostic interview. When a family had more than one child as a potential participant, the one closest to age 25 was recruited; if they were equidistant to age 25 , one was chosen randomly. The participants were informed that the purpose of the study was to examine alcohol use and childhood experiences in a variety of families. The consent rate was $87 \%$ for the 46 young-adult children (20/26 children of alcohol-dependent parents, 20/20 of social-drinking parents). The young adult subjects received $\$ 25$ for completion of an interview and self-report assessments. Interviewers were blind to the parental alcohol-dependence status.

\section{Measures}

Participants were given a multidimensional assessment that included an interview for retrospective family, economic, and reproductive life-history measures, and standardized self-report scales for attachment and social adjustment. Constructs measured were listed in Figure 1.

Early environment. Nurturing behavior of parents during early life (age 6-12) was assessed using the Home Environment Interview (HEI, Robins et al. 1985). The respondent portions were used for the present study, with the questions referring to siblings deleted. Another study of children of alcoholic parents employed a similar instrument (Reich et al. 1988). The present study used the original adult retrospective version. To create indices, sums were calculated of positive responses to yes/no questions for both mother and father separately, then summed for a parental total.

Positive Relationships between parent and child were measured by 13 items, 6 asking whether parents often spent time with the subject working around the house, playing, in outings, asking about activities, and celebrating holidays or going visiting, and other items on attending school functions, showing affection, and being easy to talk to. The subjects were also asked 
about whether parents frequently criticized the child or ever said the child was not loved, or that he or she should not have been born; scores for these items were reversed for the positive relationship total. Abusive Punishment by parents included being (1) hit with a belt or stick, (2) locked in a room for more than an hour, or (3) thrown out of the house for over an hour, or if the respondent (4) feared serious harm during parental punishment, or (5) was punished in front of nonfamily members. Higher scores reflect more abusive punishment.

Within-family variation in parental investment was represented by (1) one item from the HEI, parental discrimination (whether a parent was particularly hard on you, compared to other siblings), and (2) by birth interval between oneself and other siblings. Two years or less was considered a short interbirth interval. Other parental investment indicators related to economic resources. Parental occupations were given socioeconomic status ratings according to Featherman and Steven's index (1982). Using this scale, an electrician is coded 30 , a lawyer 87 . In addition, perceived poverty during youth was assessed by asking about family resources (potential responses ranged from, "We were poor and had a hard time paying for food and housing" to "We were well off or wealthy"; adapted from Binion, 1982). Participants also noted whether their parents had separated or divorced during childhood (before age 12).

Attachment security. Participants completed the Hazen and Shaver Adult Attachment Questionnaire (Hazen and Shaver 1987, 1990). This 13-item instrument gives scores, based on factor analysis, on three subscales that reflect these types: comfort with closeness, discomfort with closeness, and discomfort with insufficient closeness. In addition, respondents classified themselves on a three-response, forced-choice item that asks which of three statements (corresponding to avoidant, ambivalent, and secure-attachment types) best describes them. This item has a test-retest concordance of $89 \%$ (personal communication). Of the 40 subjects in this study, all but four were classified the same type by using the highest subscale or with the forced-choice item; these four were classified according to the highest subscale. There were 16 participants with nonsecure-attachment types ( 8 avoidant [ 4 men, 4 women], 5 ambivalent [2 men, 4 women], and 2 who had equal scores on avoidant and ambivalent subscales). The internal consistency of the scale items with the secure/nonsecure classification is shown in Table 1. Most items differentiated between nonsecure and secure groups. The lack of significance of a few items was due to obscured differences when avoidant and ambivalent types were collapsed (e.g., "merge completely with another person" was answered positively by most of those with ambivalent but only one of those with avoidant attachment types).

Adult relationships. The third set of measures were of adult relationships that reflect an enduring, long-term, high-investment reproductive strategy: attainment and maintenance of a marriage or cohabitation relationship (of at 
Table 1. Internal Consistency of Adult Attachment Scale: Percentage Agreeing or Strongly Agreeing with Statements

\begin{tabular}{|c|c|c|c|}
\hline Statement & Insecure & Secure & $p$-value \\
\hline $\begin{array}{l}\text { I am somewhat uncomfortable } \\
\text { being close to others. }\end{array}$ & 58.25 & 16.67 & .035 \\
\hline I find it easy to trust others. & 43.75 & 83.33 & .062 \\
\hline I find it difficult to depend on others. & 68.75 & 17.39 & .004 \\
\hline $\begin{array}{l}\text { I am nervous when anyone gets } \\
\text { too close. }\end{array}$ & 56.25 & 08.33 & .006 \\
\hline $\begin{array}{l}\text { Love partners often want me to be more } \\
\text { intimate than I feel comfortable being. }\end{array}$ & 31.25 & 16.67 & .215 \\
\hline $\begin{array}{l}\text { I find that others are reluctant to get as } \\
\text { close as I would like. }\end{array}$ & 43.75 & 16.67 & .215 \\
\hline $\begin{array}{l}\text { I often worry that my partner doesn't } \\
\text { really love me. }\end{array}$ & 50.00 & 04.17 & .038 \\
\hline $\begin{array}{l}\text { I want to merge completely with } \\
\text { another person. }\end{array}$ & 37.50 & 45.83 & .413 \\
\hline $\begin{array}{l}\text { I find it relatively easy to get close } \\
\text { to others. }\end{array}$ & 50.00 & 83.33 & .038 \\
\hline $\begin{array}{l}\text { I feel comfortable depending on } \\
\text { other people. }\end{array}$ & 31.25 & 75.00 & .032 \\
\hline $\begin{array}{l}\text { I feel comfortable having other people } \\
\text { depend on me. }\end{array}$ & 43.75 & 95.83 & .002 \\
\hline I don't often worry about being abandoned. & 56.25 & 91.67 & .012 \\
\hline $\begin{array}{l}\text { I don't often worry about someone getting } \\
\text { too close to me. }\end{array}$ & 56.25 & 95.83 & .010 \\
\hline
\end{tabular}

least a year's duration), older age at marriage, and longer courtship length. Interrupted relationships were defined as those with divorces or separations. Only eight participants had children as yet, precluding analysis of that measure.

The Social Adjustment Scale (Weissman and Bothwell, 1975) was also used, which is a self-report measure of functioning in various role areas: work, marital, social and leisure (friends), parental, family, and economic. Scale scores are averages of frequency-type items on a scale of 1-5. A general social-adjustment score is an average of all items. The scales that relate to functioning in relationships are the marital and fricndship (social/lcisure) relationship scales. For example, marital-relationship questions ask about the frequency of arguments, talking about feelings or problems, being demanding, being bossed around, feeling dependent, feeling affection, and having and enjoying intercourse. Friendship questions ask about the frequency in the past two weeks of talking with friends on the telephone, talking about problems or feelings with friends, going out socially, having arguments with friends, having one's feelings hurt, feeling shy or uncomfortable with people, feeling lonely, and so forth. Higher scores reflect poorer social adjustment.

\section{Data Analysis}

An index of multiple risks was created by summing the number of relatively independent early environmental risks experienced. Parental occupation and 
perceived poverty were significantly related, as were positive relationship with mother and abusive punishment (see below). Therefore, five risks were cumulated into an index of multiple risks: parental occupation below the group median (58.5), positive relationship with mother below the median (11.5), intersibling birth interval of two years or less, separation or divorce of parents, and discrimination by a parent. A comparable cumulative measure of adultrelationship pattern was not created; several measures apply only to persons with marital or cohabiting relationships. However, one measure was considered representative of the construct and applicable to all subjects: friendship adjustment (SASR social/leisure subscale).

Data were analyzed by calculating associations among the three sets of variables. A variety of tests were used, based on the distribution of the measures, including Spearman's correlations, Student's $t$ tests, Wilcoxon's rank sum tests and chi-square tests (likelihood ratio chi-square). Because the Social Adjustment Scale gives lower scores for "better" adjustment, the signs of correlations with this measure have been reversed to facilitate interpretation. Since specific associations were predicted between attachment security and early environment and adult relationships, no corrections for multiple tests were made. However, when associations within constructs were analyzed, such as interrelationships of early environment measures, the Bonferroni correction was used. Tables of results show either the mean and standard deviation or the median and interquartile range, depending on the statistical test employed. Since the sample size was restricted, only one multivariate analysis was conducted (linear regression). The continuous measure of friendship adjustment was tested for an independent association with attachment security beyond its association with the multiple risk measure.

\section{RESULTS}

\section{Associations of Early Environment with Attachment Security}

Attachment security was affected by the early environmental indicators of predictability and amount of parental investment during childhood (Table 2). Individually, these indicators had small effects that were in the predicted

Table 2. Associations Between Attachment Security and Early Parental Investment

\begin{tabular}{lccc}
\hline Measure & $\begin{array}{c}\text { Insecure } \\
(n=16)\end{array}$ & $\begin{array}{c}\text { Secure } \\
(n=24)\end{array}$ & $p$-value (stat) \\
\hline Occupation of mother and father & $55.20 \pm 23.15$ & $56.13 \pm 18.56$ & $\begin{array}{c}\text { n.s. }(\mathrm{t}) \\
\text { Perceived poverty }\end{array}$ \\
Caretakers divorced or separated & $56.25 \%(9 / 16)$ & $33.33 \%(8.24)$ & $.151\left(\chi^{2}\right)$ \\
Positive relationship with mother & $91.25 \%(5 / 16)$ & $12.50 \%(3 / 24)$ & n.s. $\left(\chi^{2}\right)$ \\
Abusive punishment & $1.31 \pm 2.12$ & $11.50 \pm 1.84$ & $.003(\mathrm{t})$ \\
Short intcrbirth intcrval & $56.25 \%(9 / 16)$ & $1.13 \pm 1.78$ & n.s. (t) \\
Parents were especially hard & $31.25 \%(5 / 16)$ & $37.50 \%(9 / 24)$ & $n . s .\left(\chi^{2}\right)$ \\
\hline Two risks & $75.00 \%(12 / 16)$ & $45.83 \%(11 / 24)$ & $.063\left(\chi^{2}\right)$ \\
Three risks & $50.00 \%(8 / 16)$ & $8.33 \%(2 / 24)$ & $.068\left(\chi^{2}\right)$ \\
\hline
\end{tabular}


Table 3. Associations Between Attachment Security and Adult Relationships

\begin{tabular}{lccc}
\hline Measure & $\begin{array}{c}\text { Insecure } \\
(n=16)\end{array}$ & $\begin{array}{c}\text { Secure } \\
(n=24)\end{array}$ & $p$-value (stat) \\
\hline Attained married/cohabiting relationship & $37.5 \%(6 / 16)$ & $62.5 \%(15 / 24)$ & n.s. $\left(\chi^{2}\right)$ \\
Age at first relationship & $21(19-22)$ & $23(21-25)$ & $.050(\mathrm{Wz})$ \\
Duration of courtship & $6.5(5-12)$ & $24(12-36)$ & $.021(\mathrm{Wz})$ \\
Interrupted relationships & $66.7 \%(4 / 6)$ & $33.3 \%(5 / 15)$ & n.s. $\left(\chi^{2}\right)$ \\
Social adjustment: & & & \\
$\quad$ Marital & $2.55 \pm 1.10$ & $1.59 \pm 0.33$ & $.012(\mathrm{t})$ \\
$\quad$ Friendship & $2.20 \pm 0.66$ & $1.72 \pm 0.30$ & $.014(\mathrm{t})$ \\
$\quad$ Overall & $1.96 \pm 0.43$ & $1.65 \pm 0.20$ & $.003(\mathrm{t})$ \\
\hline
\end{tabular}

direction. Trends were present for nonsecurely attached subjects to have a perception of a poorer early lifestyle, a worse relationship with mother during years 6-12, and to feel a parent was "particularly hard on me, of all the children." Of the seven who reported that a parent was especially hard on them, only two showed a secure attachment style.

Environmental risk measures were relatively independent, except that parent's occupations and perceived poverty were significantly related; the average prestige score was $47.5 \pm 18.7$ for those who perceived themselves to be poor, compared to $61.9 \pm 19.5$ for those who were comfortable $(t(38)=$ $-2.35, p=.024)$. However, the two economic measures were not significantly related to other investment measures. Perceived parental discrimination appeared to be associated with parental occupational prestige; participants who felt that parents were especially hard on them reported lower prestige scores $(38.7 \pm 19.4)$ than participants who did not so feel $(61.8 \pm-13.1 ; t(17)=$ $3.11, p=.031$ ), but the small sample of only seven who felt unfavored (among the 18 who felt parents showed discrimination) limits the reliability of this finding. Participants with a short intersibling interval tended to experience moit abusive punishment by parents $(1.89 \pm-2.42)$ than participants with longer intersibling intervals $(0.64 \pm 1.09 ; t(38)=-2.03, p=.054)$. Having experienced parental separation or divorce was not significantly related to other measures.

The multiple risk index also differed for the secure and nonsecure groups. When several risks were present, the effect on attachment security was strong (Table 2). Two risks were present for 23 people, 12 of whom were nonsecure, compared to only 4 nonsecure of the 17 others. Three or more risks were present for 10 people, 8 of whom were nonsecure, compared to 8 nonsecure of the 30 without three or more risks.

\section{Attachment Security and Adult Relationships}

Attachment security was clearly related to current relationships (Table 3 ). The nonsecurely attached subjects were somewhat less likely to have attained enduring marriages. Only 6 of the 16 nonsecure had married or cohabited 3 of these were marriages); 15 of the 24 securely attached participants had cohabitation or marital relationships (11 were married). The $6 / 16$ nonsecure who had 
a marriage or cohabitation began them at a younger age and after a shorter dating period than did the $15 / 24$ secure with such relationships. Separations or divorces had already occurred in the relationships of $4 / 6$ nonsecure versus $5 / 15$ secure. Only 8 of the young adults had children, $6 / 24$ of the secure group (4/13 men, $2 / 11$ women) and $2 / 16$ nonsecure ( $0 / 7$ men, $2 / 9$ women). 'The nonsecurely attached subjects reported worse social adjustment both with friends (social and leisure activities) and with marital partners (based on the 6 nonsecurely attached who were married).

Measures of adult relationships were not independent. Marital and social adjustment had a Spearman correlation of $.75(p=.0005)$. The older the age at first marriage or cohabitation, the longer was courtship duration $\left(r_{\mathrm{s}}=.39, p=\right.$ .08). Those whose relationships were already terminated had begun them at about age 21, two years younger than those whose relationships were still intact $(20.89 \pm 1.96$ vs $23.08 \pm 2.39 ; t(19)=2.306, p=.037)$. General social adjustment scores were better for those with an older age at first relationship $\left(r_{\mathrm{s}}=.63, p=.002\right)$ and a longer dating period $\left(r_{\mathrm{s}}=.48, p=.027\right)$; it was not associated with having interrupted marriages, however.

\section{Sex Differences}

Since men and women might differ on average in attachment security, relationship patterns, and environmental predictors, associations of interest were examined within sexes. First, men and women were compared on demographic measures and attachment security. Male subjects did have about one more year of education on average $(\bar{x}=15.00 \pm 1.85$ vs $13.70 \pm 1.90, t(38)=2.19, p=$ $.035)$, and they were generally in a higher income category $(\bar{x}=8.40 \pm 2.70 \mathrm{vs}$ $6.30+2.55, t(38)=2.52, p=.016 ; \$ 15,000-19,000 /$ year vs $\$ 7,000-9,999$ ). Male and female subjects did not differ on number of marriages. The three subscales of the Hazen and Shaver Adult Attachment Scale did not differ by sex (all $p$ s $>.40$; Discomfort with closeness: $x=10.25 \pm 3.13$ Men vs $9.40 \pm$ 4.07 Women; Comfort with closeness $\bar{x}=10.95 \pm 1.82$ Men vs $10.70 \pm 2.87$ Women; and Discomfort with insufficient closeness $\bar{x}=8.20 \pm 1.47$ Men vs $8.60 \pm 2.26$ Women).

The nonsecure subgroup $(n=16)$ contained 7 men and 9 women, and the secure subgroup $(n=24)$ contained 13 men and 11 women. Early parental investment measures were lower for nonsecure subjects within sexes. The effect of early risks on women's attachment was apparent for those with three or more risks (nonsecure: $5 / 9$; secure: $1 / 11, x^{2}=5.09, p=.024$ ), but was not statistically significant with two or more risks (nonsecure: 7/9; secure: $5 / 11, x^{2}$ $=2.16, p=0.142$ ). Most of nonsecure men had experienced two or more risks $(5 / 7)$, as did half of the secure group $\left(6 / 13 ; x^{2}=1.17, p=0.279\right)$. One of the secure men had three or more risks (1/13), compared to $3 / 7$ of the nonsecure group ( $\left.x^{2}=3.52, p=.061\right)$.

The association of adult relationships with attachment security existed for both men and women, but varied by relationship measure used. Only 1 of the 7 
nonsecure men, and 5 of the 9 nonsecure women, had a marriage or cohabitation relationship (compared to $8 / 13$ secure men, $x^{2}(1)=4.11, p=.043$; and $7 / 11$ secure women, $\left.x^{2}(1)=1.35, p=.714\right)$. The 5 nonsecure women had married at a younger age (median $=21$ vs $24, z=-1.717, p=.090$ ), after a shorter courtship (median months $=6$ vs $30, z=-1.959, p=.050$ ). The differences in social adjustment measures by attachment security within each sex mirrored the differences between the overall secure and nonsecure groups. With the small sample size, however, attachment-security group differences in friendship social adjustment and overall adjustment were significantly only for women (Friendship $\bar{x}=2.35 \pm 0.70$ Nonsecure vs $1.80 \pm 0.38$ Secure, $t(18)=$ 2.25, $p=.037$; Overall $\bar{x}=2.05 \pm 0.35$ Nonsecure vs $1.68 \pm 0.24$ Secure, $t(18)=2.78, p=.012$ ), not for men (Friendship $\bar{x}=2.00 \pm 0.59$ Nonsecure vs $1.66 \pm 0.22$ Secure, unequal variance $t(6.9)=1.49, p=.180$; Overall $\bar{x}=1.86$ \pm 0.53 Nonsecure vs $1.62 \pm 0.15$ Secure, unequal variance $t(6.5)=1.18, p=$ $.281)$.

In summary, the effect of attachment security on adult relationships was shown for men in the probability of having a relationship of at least one year. For women, the association occurred for age at the first relationship, duration of courtship, and social adjustment.

\section{Early Environment and Adult Relationships}

From these analyses, attachment security appeared to be an important mediator of the effects of early environment on adult relationships. However, early environment might have direct independent associations with adult relationships, regardless of attachment. Therefore, we examined the univariate relationships of the early environment measures to adult relationships and also conducted several regression analyses involving both attachment security and early environmental risk. Most of the univariate relationships were not as strong as the associations between the measures of adult relationships and the measure of attachment security; attachment security seems to summarize well the relevant other variables. None of the interrelationships examined (of 42 associations or correlations) reached a nominal significance level of $p<.05$. Some trends occurred, however, that may warrant future investigation. Age at first relationship tended to be older when parental occupational prestige was higher $\left(r_{\mathrm{s}}=.396, p=.075\right)$; friendship social adjustment tended to be better when one's relationship with mother had been positive $\left(r_{\mathrm{s}}=.295, p=.065\right)$. For those who had married or cohabitated, the frequency of relationship termination tended to be higher when intersibling interval was shorter (short IBI, 5/7 terminated vs longer IBI, 4/10 terminated, $x^{2}(1)=3.56, p=.059$ ) and when respondents felt parents were particularly hard on them (parents hard, $4 / 4$ terminated vs parents not hard, $2 / 7$ terminated, F.E.T. $p=.061$ ).

The multiple risk summary measure did show univariate associations with adult relationship measures. For example, only 1 of 10 participants with three or more risks had an enduring first marriage or cohabitation (no divorce or 
separation), compared to $11 / 30$ with fewer risks $\left(x^{2}(1)=2.938, p=.087\right)$. Friendship adjustment had a correlation of .412 with multiple risks $(p=.008)$. However, when the effect of attachment security was modeled simultaneously, the risk correlation became nonsignificant. Attachment security had a significant independent association with friendship adjustment, after accounting for the effects of multiple risks $(F(1,37)=5.64, p=.023$; with both in the equation: $\left.F(2,37)=5.89, p=.006 ; R^{2}=.24\right)$. Overall, attachment security was a useful construct for linking rearing environment with subsequent relationship functioning.

\section{DISCUSSION}

Results of this study support an association among early environment, adult attachment security, and adult relationships. Adults with nonsecure attachment models were much more likely to have experienced several indicators of unpredictable or scarce resources, compared to secure adults. This study assessed childhood resource adversity primarily in terms of parental investment. The magnitude and predictability of parental investment during childhood was classified as lower if there was a brief intersibling interval, parental divorce, fewer economic resources, or less nurturing parents. Several such indicators were present for 17 people, 12 of whom were nonsecure, compared to only 4 of the 23 in the lower risk group. Attachment security was associated with the likelihood of attaining a marital relationship after a lengthy courtship. The nonsecurely attached participants were less likely to have attained enduring marriages. The $6 / 16$ nonsecure who had a marriage or cohabitation began them at a younger age and after a shorter courtship period than did the 15/24 secure with such relationships. Separations or divorces had already occurred in the relationships of $4 / 6$ nonsecure versus $5 / 15$ secure. Results are consistent with theories that unpredictable early environments foster younger, shorterterm (rather than later, long-term) mating strategies (or in refraining from forming a marital relationship), possibly through affecting attachment styles (Dickemann 1986; Draper and Belsky 1990).

Attachment security was associated with parental investment measures and adult rélationships for men and women, when analyzed separately. Men and women did, however, show somewhat different responses to early environmental factors. For men, the effect of a nonsecure attachment model on adult relationships was manifested in a lower probability of attaining a lasting cohabitation or marital relationship. Women with insecure attachment often had relationships, but the age at first relationship was younger and the duration of courtship was shorter for them than for women with secure attachment models. This sex difference may reflect a propensity of men to have relationships that do not involve cohabitation. The instruments used in this study recorded relationships that involved cohabitation or mutual children, not all relationships. More probably this difference reflects the greater difficulty for men than women to obtain a mate, in general. The evolutionary basis of such a 
sex difference has been proposed as the sex difference in requisite parental investment (Trivers 1972). Studies of nonindustrial societies do show that men's reproductive lives are more variable than womens, in terms of reproductive success (reviewed in Daly and Wilson 1983).

In our model, the salient dimensions of early environment are the predictability and amount of parental investment. These factors are expected to affect the timing of first reproduction attempts, a focus which is somewhat different from that of Draper, Belsky and colleagues (Belsky et al. 1991; Draper and Belsky 1990). Instead they focused on variation along a parental investment continuum of "quality versus quantity," which is a model uscd in many comparative studies in animal behavior (reviewed in Borgerhoff Mulder, 1992). This focus was criticized by Maccoby (1991). There is little evidence for a positive correlation of an early onset of reproduction with final family size, or on the eventual number of offspring of those who begin life with various levels of environmental unpredictability. The correlation between age at onset of reproduction and final family size is unclear, particularly because it may be changing over time (reviewed in Furstenberg et al. 1987, pp. 34-40). When measured in their early thirties, early childbearers had about .5-1.0 more children than later childbearers, according to several national surveys (reviewed in Furstenberg et al.). However, later childbearers may continue longer and catch up. Early childbearers show a "rapid tempo of family building," but appear to terminate their reproductive careers earlier, particularly in geographical areas where abortion and sterilization are available (Furstenberg et al.). If these patterns are common, early reproduction may not lead to more reproduction, but primarily may represent a shift in timing.

For humans, the adaptive problem might thus be whether the present is a propitous time for parental investment in a child versus other alternatives for inclusive fitness (Hill and Low, 1992). Those alternatives are investing somatic effort in oneself now to prepare for better reproductive opportunities later, or investing in reproduction of kin. When resources are scarce but predictable, the best strategy would be to save resources for a better time, and to reproduce when a threshold level is reached. Scarcer resources might result in reproductive shutdown, as Maccoby (1991) argued, when the best strategy is to divert resources to other kin and have no children of one's own. In the present study, many of those with nonsecure attachment styles did not form relationships or have children. Only 6/16 nonsecure yet had a cohabitation or marital relationship lasting at least a year, compared to $15 / 24$ securely attached persons. When resources are unpredictable, however, one cannot expect that the future will be better. If a threshold level of resources happened to become available, one's hest het would be to reproduce (Dickemann 1986; Rubenstein 1982). These predictions follow the logic of bet-hedging theory, which tracks reproductive success by the number of generations that a lineage survives; having fewer offspring may enhance long-term reproductive success when their probability of successfully reproducing is increased by investment (Hirschfield and Tinkle 1975; Williams 1966; Wittenberger 1981). 
The interrelationships of resource distribution, parental effort, and investment in specific offspring are complex. Comparative studies consistently show that parental investment decreases as resource availability decreases (reviewed in Clutton-Brock, 1991). However, age at which offspring become independent and investment is terminated may not be the best measure of parental investment; duration of investment may be brief in environments with abundant resources while magnitude of investment remains high. Lee et al. (1991) proposed a U-shaped relationship between resource availability (maternal condition) and termination of investment (weaning age), based on analyses of intraspecific variation among large-bodied mammals. Longer duration of investment would be associated with mild food limitation, whereas scarce or abundant resources could be associated with briefer investment periods and earlier weaning. Clearly, human life history theory must be further elaborated to develop more specific predictions about the joint effects of resource distribution and the age-specificity of mortality.

A retrospective study cannot address cause and effect, since poor adult relationship outcomes might bias recall of parental behavior. The role of attachment security as a psychological mechanism mediating behavior is unclear from a correlational retrospective study such as this. In the conceptual model, early environment affects attachment security, which is a stable characteristic that is resistant to later change. However, the environment may change; an ideal organism might show total flexibility in relationship patterns in order to respond to current conditions. However, learning during sensitive periods, rather than completely flexible learning, may be optimal under some conditions, depending on the pattern of environmental change over time (Chisholm 1993). In the present study, attachment security seemed to be a good proxy for measuring success in relationships. Few of the nonsecurely attached people had serious relationships of over a year's duration, and those who did had begun them at a younger age after a shorter dating period. The security measure was more associated with the relationship variables than the early environment measures alone.

Future research could beneficially address the roles of specific aspects of childhood adversity and environmental risks in relationship formation. Chisholm (1993) proposed that high mortality is translated into proximate stress and less-involved parenting. Attachment theory could predict relationship dysfunction from less-involved parenting and other childhood adversity without the use of evolutionary theory (Belsky, personal communication). However, we used life-history theory to create a novel measure of early environmental resources in terms of parental investment, including the interbirth interval, number of sibs, and perceived parental discrimination. Conceptualizing resources and parental nurturance as parental investment allows application of life-history theory to understanding the sequelae of childhood adversity. In addition, it is important to note that the accumulation of risks is critical. Thus, losses or inadequacies in one area can be ameliorated by strengths in another area. Specific risks may not be particularly salient alone 
(even father absence), but they usually signal deficiencies in several other areas (such as low resources and less nurturance).

In addition, differences in adversity for children in the same families have not been sufficiently explored. Increasingly, research is examining withinfamily variation and effects of nonshared environment. In some cases, behavior patterns may appear to be a product of family-level selection, when one individual's behavior is seen as the manipulated result of a parent's reproductive strategy. These family-level concepts have been applied to human reproductive strategies by Dickemann (1986). She proposed that in unpredictable or diverse environments, families as units may differentiate children into highly divergent strategies to hedge their reproductive bets. Future research could test expectations derived from this perspective, particularly concerning unpredictability and sibling differences; for example, more parental discrimination and more variation among children may occur in environments that are highly unpredictable.

This study was supported in part by Center Grant No. P50 AA07378 from the National Institute of Alcoholism and Alcohol Abuse. The authors thank Kathleen Singer, Virginia Newton, and Ana Iacob for assistance in data collection and management, and Patricia Draper, Jay Belsky, James Chisholm, and Lisa Thomson Ross for their critical comments. Findings were presented at the Human Behavior and Evolution Society Meeting, August, 1991.

\section{REFERENCES}

Ainsworth, M., Blehar, M., Waters, E., and Wall, S. Patterns of Attachment, Hillsdale, NJ: Erlbaum, 1978.

Bell, C.C., and Jenkins, E.J. Community violence and children on Chicago's Southside. Psychiatry 56: 46-54, 1993.

Belsky, J., Steinberg, L., and Draper, P. Childhood experience, interpersonal development, and reproductive strategy: an evolutionary theory of socialization. Child Development 62: $647-670,1991$.

Binion, V.J. Sex differences in socialization and family dynamics of female and male heroin users. Journal of Social Issues 38: 43-57, 1982.

Bowlby, J. Attachment and Loss: Vol. l.Attachment, New York: Basic Books, 1969.

Burgerhoff Mulder, M. Reproductive decisions. In Evolutionary Ecology and Hurnan Behavior, E.A. Smith and B. Winterhalder (Eds.). New York: Aldine, 1992, pp. 339-374.

Burton, L. Teenage childbearing as an alternative life-course strategy in multigeneration black families. Human Nature 1: 123-143, 1990.

Chisholm, J. Death, hope, and sex: life history theory and the development of reproductive strategies. Current Anthropology 34: 1-12, 18-24, 1993.

Clutton-Brock, T.H. The Evolution of Parental Care, Princeton, NJ: Princeton University Press, 1991.

Daly, M., and Wilson, M. Sex, Evolution, and Behavior, (2nd. Ed.) Belmont, CA: Wadsworth, 1983.

Dickemann, M. Multiple genders and reproductive strategies in humans: steps toward a radical sociobiology. Paper presented at the Anthropology Colloquim series, University of Michigan, Ann Arbor, October 7, 1986.

Draper, P., and Belsky, J. Personality development in evolutionary perspective. Journal of Personality 58: 141-162, 1990.

Draper, P., and Harpending, H. Father absence and reproductive strategy: an evolutionary perspective. Journal of Anthropological Research 38: 255-273, 1982. 
Emlen, S.T., and Oring, L.W. Ecology, sexual selection, and evolution of mating systems. Science 197: 215-223, 1977.

Featherman, D.L., and Stevens, G. A revised socineconomic index of occupational status: application in analysis of sex differences in attainment. In Social Structure and Behavior: Essays in honor of William Hamilton Sewell, New York: Academic Press, 1982.

Furstenberg, F.F. Jr., Brooks-Gunn, J., and Morgan, S.P. Adolescent Mothers in Later Life, Cambridge, England: Cambridge University Press, 1987.

Hazen, C., and Shaver, P.R. Romantic love conceptualized as an attachment process. Journal of Personality and Social Psychology 52: 511-524, 1987.

Hazen, C., and Shaver, P.R. Love and work: an attachment-theoretical perspective. Journal of Personality and Social Psychology 59: 270-280, 1990.

Hill, E.M., and Low, B.S. Contemporary abortion patterns: a life history approach. Ethology and Sociobiology 13: 35-48, 1992.

Hill, E.M., Nord, J., and Blow, F.C. Young-adult children of alcoholic parents: protective effects of positive family functioning. British Journal of Addiction 87: 1167-1690, 1992.

Hirschfield, M.F., and Tinkle, D.W. Natural selection and the evolution of reproductive effort. Proceedings of the National Academy of Sciences USA 72: 2227-2231, 1975.

Krebs, J.R., and Davies, N.B. Behavioural Ecology: An Evolutionary Approach. Sunderland, MA: Sinauer Associates, 1984.

Lancaster, J., and Lancaster, C. The watershed: change in parental-investment and familyformation strategies in the course of human evolution. In Parenting across the Lifespan: Biosocial Dimensions, J. Lancaster, A. Rossi, J. Altmann, and L. Sherrod (Eds.). New York: Aldine, 1987, pp. 187-205.

Lee, P.C., Majluf, P., and Gordon, I.J. Growth, weaning and maternal investment from a comparative perspective. Journal of Zoology 225: 99-114, 1991.

Maccoby, E.E. Different reproductive strategies in males and females. Child Development 62 : 676-681, 1991.

Promislow, D., and Harvey, P. Living fast and dying young: a comparative analysis of life-history variation among mammals. Journal of the Zoological Society of London 220: 417-437, 1990.

Promislow, D., and Harvey, P. Mortality rates and the evolution of mammal life histories. Acta Oecologica 12: 119-137, 1991.

Reich, W., Earls, F., and Powell, J. A comparison of the home and social environments of children of alcoholic and non-alcoholic parents. British Journal of Addiction 83: 831$839,1988$.

Robins, L., Schoenberg, S.P., Holnes, S.J., Ratcliff, K.S., Benham, A., and Works, J. Early home environment and retrospective recall: a test for concordance between siblings with and without psychiatric disorders. American Journal of Orthopsychiatry 55: 27-41, 1985.

Rubenstein, D.I. Risk, uncertainty and evolutionary strategies. In Current Problems in Sociobiology, King's College Sociobiology Group (Eds.). Cambridge, England: Cambridge University Press, 1982, pp. 91-111.

Sroufe, L.A. The coherence of individual development. American Psychologist 34: 834-841, 1979.

Surbey, M.K. Family composition, stress, and the timing of human menarche. In The Socioendocrinology of Primate Reproduction. F.B. Bercovitch and T.E. Zeigler (Eds.). New York: Alan R. Liss, 1990, pp. 71-97.

Trivers, R. Parental investment and sexual selection. In Sexual Selection and the Descent of Man: 1871-197I, B. Campbell (Ed.). Chicago: Aldine, 1972, pp. 136-179.

Turke, P. Evolution and the demand for children. Population and Development Review 15: $61-90,1989$.

Weissman, M.M., and Bothwell, S. Assessment of social adjustment by patient self-report. Archives of General Psychiatry 33: 1111-1115. 1975.

Williams G.C. Adaptation and Natural Selection: A Critique of Some Current Evolutionary Thought, Princeton, NJ: Princeton University Press, 1966.

Wittenberger, J.F. Animal Social Behavior, Boston: Duxbury, 1981. 